\title{
A Survey Evaluation of the Midwifery Pre-Qualifying Skills Passport in Wales
}

\section{Background}

Four universities in Wales offer validated Midwifery Pre-Registration Education Programmes and they all include assessment and grading of practice in line with the NMC Standards for Preregistration Midwifery Education (NMC, 2009). Midwifery Students in Wales echoed the findings of previous studies, which had reported a lack of self-confidence at the point of registration (Donovan, 2008; Skirton et al., 2013). However, it was noted at all-Wales meetings between lead midwives for education and heads of midwifery that newly qualified midwives felt ready for practice, but they specifically lacked confidence in some technical midwifery skills. This was reported to be due to lack of exposure to these skills or unwillingness of mentors to support them to acquire them (Darra et al, 2016). Mirzakhani \& Shorab (2015) found that clinical skills acquisition had a positive correlation with self-confidence, particularly in relation to 'high-risk' care. The ability to practise skills to develop confidence and self-efficacy in a supportive environment was found to contribute to development of competence and knowledge by Bäck et al (2017). Whilst both these studies were conducted outside the UK, findings resonate with the feedback from student midwives in Wales. The newly qualified midwives also felt frustrated by the need to're-demonstrate' their ability to undertake certain skills after Registration which echoed previous research by Hughes and Fraser $(2011$, p.386) who suggested collaboration between Trusts and Universities 'to identify the sort of evidence that the employers require for some of the skills identified as necessary in their 'preceptorship packages'. When exploring the transition experiences of newly qualified midwives, Avis et al. (2012) recommended that Midwifery Managers should encourage senior students to be given more responsibility during their final placements.

It became clear, however, that there was no published research that explicitly explored newly qualified midwives' confidence and competence in undertaking particular technical skills. Despite this, and in response to identified need in Wales and the recommendation from Hughes and Fraser 
(2011), representatives from universities and Health Boards in Wales worked together to develop a standardised approach to ensuring that midwifery students are supported to take responsibility and develop the identified skills BEFORE they qualify and register with the NMC. All four higher education insitutions in Wales and the seven Health Boards collaborated over an extended period to develop the All Wales Pre-Qualifying Skills Passport (PQSP).

The PQSP was not developed explicitly to increase the NQMs' overall confidence in transitioning into registered status. Alongside acquisition of all the essential skills clusters (NMC, 2009), the PQSP was designed as a tool to enable student midwives, under mentor supervision, to practise 16 identified midwifery technical skills during the undergraduate programme, so that their ability to undertake the skills would be at the appropriate level for a newly qualified midwife at the point of registration. This should prevent duplication in the preceptorship period.

While not all educational theorists support the concept that knowledge acquisition should precede practice (Kermode, 1984; Lave and Wenger, 1991; Eraut, 1999; Edmond, 2001), it was agreed by consensus to design the PQSP using classical educational theory (Biggs, 1999; Vygotsky, 1978). It was comprised of two sections:

Section one incorporates the theory /underpinning knowledge behind the skills - usually discussed during university theory learning.

Section two sets out each clinical skill in a stepped approach to be used in the practice learning environment by the student under direct supervision of a midwifery mentor.

The 16 skills were identified through review of preceptorship needs assessments, in-depth discussion and consensus within the Health Boards and the HEls (Darra et al, 2016) (Table 1). These were identified as the particular technical skills that are expected of a newly qualified midwife but were consistently noted as being those that new midwifery registrants in Wales were most commonly unable to undertake. This had led to criticism of the pre-registration programmes and the need for intensive training within the already extensive preceptorship programmes. 
Following a brief pilot phase the PQSP was launched across Wales by the Chief Nursing Officer for full implementation in August 2014. Given the number of skills in the passport and the need for suitable opportunities to arise in order to practice the skills, it was decided that the passport could not be completed during their final practice placement. The PQSP was therefore introduced to all second year student midwives giving them 2 years to complete the skills in different clinical areas. Whilst its completion is not a requirement of the degree award, all students are encouraged to achieve all the skills in the PQSP and to highlight this at job interviews on qualification.

The aim of the study reported here was to evaluate the use of the PQSP from the perspectives of midwifery students, midwife mentors, newly qualified midwives, midwifery managers and midwifery teachers.

\section{Method}

Evaluation of the Pre-Qualifying Skills Passport (PQS) was integral to its original development when it was decided that a brief, anonymous, self-administered paper questionnaire should be distributed 2 years after its launch. This method was selected as an appropriate way to achieve a good response rate. It was recognised that student midwives received a large number of evaluation requests from the university via e-mail, resulting in the potential for the survey to be lost amongst other requests. As clinical midwives report a lack of time to read e-mails, a paper survey was likely to achieve a better response rates well as protecting anonymity, which could not be guaranteed if linked to email addresses. The exact number of potential respondents was not known as the numbers of mentors, managers and students available to complete the questionnaire during the specific time periods varied across the sites.

The study was viewed as a service/education evaluation; therefore ethical review by the university or the Local Health Board ethics committees was not required. However, the usual conventions of anonymity and confidentiality (Eby, 2000) were upheld through ensuring that the questionnaires were anonymous. So that the respondents did not inadvertently breach this, the questionnaire did 
not have space for any identifying information and it included a request to not include any information that could identify any places or people.

After discussion within all four HEls the final questionnaire comprised 9 statements with 4-level Likert-scale responses. Space was provided beneath each response to add further comments. The authors selected to use a 'forced response' (Wivagg, 2011) to eradicate a nonresponse middle option (commonly presented as 'don't know', 'not sure,' or something similar). The questionnaire was kept simple and each question was set out as in Table 2.

Table 3 shows the evaluation form. Statements 1, 3 and 6 related to how the PQS is used by Students and their Mentors; statements 2, 7 and 8 related to the structure and style of the document as well as its ease of use (or otherwise); statements 4 and 5 related to the content of the PQSP; and statement 9 referred to whether such a document was needed at all. In order to ensure that autonomy was respected, the rationale for the study was explained and completion of the questionnaire was accepted as being full and free consent to taking part. The anonymous self-administered paper questionnaires were distributed on a rolling programme in three Welsh Universities over a 1 year period by giving it out to second and third year students when they were in university for lectures and practical classes. questionnaires were distributed widely to mentors and newly qualified midwives by practice facilitator midwives, and to midwifery lecturers and midwifery managers by the authors.

All those in receipt of the anonymous questionnaire were specifically informed that it was the key instrument for an evaluation study seeking the honest and valuable views of the participants. The heading to the questionnaire stated that the study was being undertaken by the heads of midwifery education who were conducting the evaluation to inform future debates and improvements in midwifery education. Prospective participants were also expressly instructed to complete the questionnaire only once before returning it to their local University. The questionnaires were returned in several ways: students brought them to university and placed them in a pile for collection by their lecturers; mentors handed them back to facilitator midwives for return to the 
universities; managers posted them to the authors; and lecturers returned theirs with others to the authors. Completed questionnaires were handed to the authors in piles, resulting in it being virtually impossible to identify the participants.

During the evaluation period, 167 questionnaires were returned and analysed and Table 4 shows the number of responses from different groups of participants. While it may be considered useful to stratify the sampling (Polit \& Beck, 2012,) in order to consider responses from different categories of participants (such as second or third year students), this study did not stratify either the sampling or the data, due to the relatively small final sample size. However stratification is planned for further evaluation of the PQS (planned for 2019).

This article reports on the numbers and 'types' of respondents, and the numbers and percentages of responses to each question. Descriptive quantitative data will be discussed here using numbers and percentages, and supported by brief references to qualitative data collected in the 'free text' sections of the questionnaire.

\section{Findings}

The simple descriptive findings are displayed in Table 3. It should be noted that not all respondents answered all the statements. No reasons were offered for not answering particular questions, but all the answers that were offered were checked by two authors and all these were included.

\section{Discussion}

The questionnaire was designed to reflect four areas of evaluation: the purpose of the PQSP; the structure and style of document and ease of use; information included and suggestions for changes; and whether a PQSP was needed at all. The findings will now be discussed in terms of these areas of evaluation. 


\section{The purpose of the PQSP}

Statements 1, 3 and 6 related to the intended usefulness of the PQS in practice. It was considered important to evaluate this aspect since if a tool is not thought to have a defined use and aim then there is potential for it to be ignored, especially in busy practice settings.

It appears that a large majority (over 97\%) of respondents either completely agreed or slightly agreed that: 'using the passport ensures that opportunities are found for students to practice vital skills prior to qualification'. This is encouraging for the authors of the passport, since this was one of the chief driving factors for its inception (Darra et al., 2016). A large proportion of those who responded to statement $6(74 \%)$ went further and either completely agreed or slightly agreed to the statement: 'Without the Passport some students may qualify without trying out essential midwifery skills'. This reflects Avis et al.'s recommendation to ensure that students have the opportunity to practice key clinical with support prior to qualification.

However, it is interesting to note that 38 respondents did not answer this question. One cannot be sure why this was the case but it may have been because they did not agree nor disagree with this slightly stronger statement. In future evaluations the authors will consider seriously using a 5 point scale including a middle choice for those who may neither disagree nor agree with a statement (Allen \& Seaman, 2007).

When being asked to assess whether they agreed or disagreed with the statement: 'The Passport helps me to know what is expected of newly qualified midwives in terms of the identified skills', the response was definitive with 112 of the $167(67 \%)$ respondents stating that they completely agreed and a further $50(30 \%)$ who slightly agreed with this statement. This was reassuring since it was the reported confusion about the skills required of newly qualified midwives that had partially contributed to the initial development of the PQSP. 


\section{Structure and style of the PQSP and ease of use}

Statements 7 and 8 related to the structure and style of the document and statement 2 related directly to its ease of use. It was considered important to evaluate these aspects since if a tool is difficult to use then it may not be used, especially in busy practice settings.

Responses indicated that $97 \%$ of those using the passport slightly agreed or completely agreed that the passport is easy to use. This was encouraging and suggested that it would be used even when practitioners are under pressure with other work. Most (93\%) respondents also agreed that they liked the way that the Passport showed that the student had the underpinning knowledge before practicing each skill. This may have reflected their feeling that knowledge and understanding should precede practice, for example, knowledge and understanding of the layers of the perineum should precede the practice of episiotomy and suturing. The designers of the PQSP were encouraged by these responses, since they subscribed to educational theory of constructive alignment (Biggs, 1999). Roosevelt et al (2018) noted that a step-wise approach was important in helping students to become proficient in a skill.

A large proportion of respondents also agreed that they liked the way that each skill was standardised and described step-by-step. The designers of the PQSP were from across Wales and had worked together to standardise the way that each skill was described and set out; therefore it was reassuring to the design team that this aspect was so highly rated. The findings concurred with the study by Donovan (2008) that suggested that confidence and competence may be linked, with more direct supervision improving skilled performance and enhancing confidence.

\section{Content and suggestions for change}

As part of the evaluation it was considered important to assess whether what is included in the PQSP was appropriate. Respondents were offered the chance to comment on this, as well as proposing any changes or additions to the document. Questions 4 and 5 related to this. 
The answers to these two questions resulted in the most variation in answers. When asked to respond to the statement 'I think that student midwives SHOULD NOT undertake one or more of the skills identified in the Passport', 78\% of respondents completely disagreed. This was also encouraging, since the intention of the PQSP was to help ensure that students were supported to undertake the identified skills. However 35 out of 167 (almost 22\%) agreed with it. When reviewing the 'free text' comments it appeared that a number of respondents were concerned about allowing students to take part in undertaking blood sugar monitoring with adults and neonates, as some Health Boards did not permit students to do this. This reflects some of the findings from previous studies (Dunn and Hansford, 1997; May and Veitch, 1998; Grealish and Smale; 2011) that found that mentors are gatekeepers of the students' access to a range of skills. Parahoo (1992) also discovered that students commonly asked mentors to undertake skills to help them meet their developmental needs, but that mentors were often confused about what students were officially allowed to do in practice. These responses demonstrate that there may still be some work to do to ensure that midwives support students to undertake all the required midwifery skills before a student's qualification.

When responding to the statement 'I think that more skills should be added' there were even more widely ranging answers: 26 respondents completely agreed with the statement and 47 slightly agreed with this. This means that approximately $45 \%$ of respondents wanted to add more skills and approximately $55 \%$ did not. In the free-text sections several skills were suggested including intravenous cannulation, 'newborn check' (reading the full responses suggested that this appeared to refer to newborn infant physical examination) and passing a neonatal nasogastric tube. In Wales, these suggestions will be included in the ongoing discussion around the changes that will be required for new curriculum development following the NMC (2009) revision of Standards for Pre-registration Midwifery Education. Some or all may be included in the next version of the PQSP. It 
is hoped that this article can inform the discussion of the skills needed in the new proficiency standards.

\section{Is the PQSP needed?}

The final statement in the questionnaire relates to whether the PQSP was necessary and respondents were asked to indicate their agreement (or not) to the statement 'I would prefer it if mentors were able to teach the students what they want to teach them - without the use of passports such as the pre-qualifying skills passport.' The results demonstrated that $77 \%$ of the respondents felt that the PQSP was useful to support them to facilitate learning in practice; However, this indicates that a reasonable number of respondents $(n=37 ; 23 \%)$ felt that they would prefer to teach and learn practical skills without the use of passports such as the PQSP. It is encouraging that some midwives and students feel able to teach and learn everything that is required on their own initiative; but the majority appeared to appreciate additional guidance and structure for skills teaching. Donovan (2008) suggested that feedback to students and support in decision-making is important for confidence development and the PQSP is a tool to provide structure to this.

\section{Limitations}

Most importantly, this study did not seek to elicit whether students felt more confident in their practice after completing the passport; this aspect will be the focus of the next evaluation. It also did not evaluate whether midwifery managers were more assured about newly qualified midwives' ability to undertake the technical skills that they had identified as being problematic before implementation of the PQSP; this will also be a focus of the next evaluation.

In relation to the conduct of the study, there was potential for people other than the researchers to read the responses; therefore in future evaluation surveys the questionnaires will be returned in sealed envelopes. 


\section{Conclusion}

Respondents to the survey found that using the PQSP ensured that opportunities are found for students to practice vital skills prior to qualification. The findings further demonstrate that the PQSP successfully integrated knowledge with skills, helped newly qualified midwives to learn skills in a step-by-step way and was easy to use in busy practice settings. Furthermore it was found to help mentors and students to know what skills are expected of newly qualified midwives. There was also much interest in adding more skills to the PQSP in future.

The findings from this survey were generally very positive for its authors and they will be used to continue to revise the PQSP. The next stage is to consider the findings of this study alongside the new NMC Standards for Pre-registration Midwifery Education. It may be that there will be a national skills document developed as part of the current NMC revision, or it may be that the new NMC standards will not specify any explicit technical skills. If the latter is the case, then it may be important to revise and improve the PQSP and to continue to monitor its use and acceptability in practice. As technologies and evidence advance, and levels of complexity increase in relation to the care needs of women during childbearing it is likely that midwives will need to develop and perform new skills, while other may become obsolete.

There is some interest in Wales to develop the PQSP into a document that can be commenced during the pre-registration programme and continued as part of preceptorship and throughout a midwife's career. The time is right to consider in more depth some of the technical skills that midwives are expected to develop and this study has provided some insight into what students, mentors and managers want and need in practice.

\section{References}

Avis M, Mallik M, Fraser DM (2012) Practising under your own Pin- a description of the transition experiences of newly qualified midwives. Journal of Nursing Management 21: 1061-1071

Allen E, Seaman C (2007) Likert scales and data analysis. Quality Progress 40(7): 64-65 
Bäck L, Hildingsson I, Sjöqvist C, Karlström A. (2017) Developing competence and confidence in midwifery-focus groups with Swedish midwives. Women Birth. 2017 Feb;30(1): e32-e38. doi: 10.1016/j.wombi.2016.08.004.

Biggs J (1999) Teaching for Quality Learning at University. SRHE/OU, Buckingham

Darra S, Davies J, Edgerton L, Morse N, Thomas G (2016) Working together to implement a PreQualifying Skills Passport in Wales: Report of a pilot project. British Journal of Midwifery (24)7: 2-7

Donovan P (2008) Confidence in newly qualified midwives. British Journal of Midwifery (16)8: 510514

Dunn SV, Hansford B (1997) Undergraduate nursing students' perceptions of their clinical learning environment. Journal of Advanced Nursing 25: 1299-1306.

Eby MA (2000) Producing evidence ethically in: R. Gomm and C. Davies (Eds) Using Evidence in Health and Social Care London: Sage

Edmond CB (2001) A new paradigm for practice education. Nurse Education Today (21)4: 251-259.

Eraut M (1999) Developing professional knowledge and competence. London: The Falmer Press

Grealish L, Smale LA (2011) Theory before practice: Implicit assumptions about clinical nursing education in Australia as revealed through a shared critical reflection. Contemporary Nurse: $A$ Journal for the Australian Nursing Profession (39)1: 51-64

Hughes AJ, Fraser DM. Sink or swim: the experience of newly qualified midwives in England. Midwifery. 2011;27(3): 382-6

Johnson RL, Morgan GB. Survey Scales: A Guide to Development, Analysis and Reporting. London: The Guildford Press; 2016

Kermode $S$ (1984) The role of the clinical supervisor in college programs. The Australian Nurses Journal (13)6: 34-35

Lave J, Wenger E (1991) Situated learning: Legitimate peripheral participation. Cambridge: Cambridge University Press

May N, Veitch L (1998) Working to learn and learning to work: placement experience of Project 2000 nursing students in Scotland. Nurse Education Today 18: 630-636

Mirzakhani K, Shorab NJ (2015) Study of the self-confidence of midwifery graduates from Mashhad College of nursing and midwifery in fulfilling clinical skills. Electron Physician. 2015 Sep; 7(5): 12841289. doi: $10.14661 / 1284$

Nursing \& Midwifery Council (2009) Standards for pre-registration midwifery education. London, NMC

Parahoo K (1992)The reality of supernumerary status. Nursing Standard 6: 37-40. 
Polit DF, Beck CT (2012) Nursing Research: Generating and Assessing Evidence for Nursing Practice 9th edn. Philadelphia, USA, Wolters Klower Health, Lippincott Williams \& Wilkins

Roosevelt L, Diebel M, Zielinski RE (2018) Achieving competency in vaginal examinations: The challenge of balancing student learning needs with best practice in maternity care. Midwifery 61, 39-41

Skirton H, Stephen N, Doris F, Cooper M, Avis M, Fraser DM (2011) Preparedness of newly qualified midwives to deliver clinical care: An evaluation of pre-registration midwifery education through an analysis of key events. Midwifery (28)5: e660-e666

Vygotsky LS (1978) Mind in Society. Cambridge MA: Harvard University Press

Wivagg J (2011) Forced Choice. In Lavrakas PJ ed. Encyclopedia of Survey Research Methods. Sage Publications,Thousand Oaks, California: 290 
Table 1 - Skills identified for inclusion in the pre-qualifying skills passport

\begin{tabular}{|c|c|c|c|}
\hline & $\begin{array}{l}\text { Particular skill not identified in the NMC Standards } \\
\qquad(2009)\end{array}$ & $\begin{array}{c}\text { NMC (2009) } \\
\text { Standard17 Competency }\end{array}$ & $\begin{array}{c}\text { NMC (2009) } \\
\text { Essential Skill Cluster }\end{array}$ \\
\hline 1 & Speculum examination & $\begin{array}{l}\text { Effective Midwifery Practice } \\
2\end{array}$ & $\begin{array}{c}\text { Communication; Normal Labour } \\
\text { and Birth }\end{array}$ \\
\hline 2 & Membrane sweep & $\begin{array}{c}\text { Effective Midwifery Practice } \\
4\end{array}$ & Communication \\
\hline 3 & Venepuncture/phlebotomy & $\begin{array}{c}\text { Effective Midwifery Practice } \\
2\end{array}$ & Communication \\
\hline 4 & Induction of labour with prescribed p.v. medication & $\begin{array}{l}\text { Effective Midwifery Practice } \\
12\end{array}$ & $\begin{array}{l}\text { Communication; Medical } \\
\text { Products Management }\end{array}$ \\
\hline 5 & Amniotomy & $\begin{array}{c}\text { Effective Midwifery Practice } \\
4\end{array}$ & $\begin{array}{l}\text { Communication; Normal Labour } \\
\text { and Birth }\end{array}$ \\
\hline 6 & Application of FSE & $\begin{array}{l}\text { Effective Midwifery Practice } \\
6\end{array}$ & $\begin{array}{l}\text { Communication; Normal Labour } \\
\text { and Birth }\end{array}$ \\
\hline 7 & Episiotomy & $\begin{array}{l}\text { Effective Midwifery Practice } \\
7\end{array}$ & $\begin{array}{l}\text { Communication; Normal Labour } \\
\text { and Birth }\end{array}$ \\
\hline 8 & $\begin{array}{l}\text { Perineal suturing (NOT more than } 2^{\text {nd }} \\
\text { degree/episiotomy) }\end{array}$ & $\begin{array}{c}\text { Effective Midwifery Practice } \\
9\end{array}$ & $\begin{array}{l}\text { Communication; Normal Labour } \\
\text { and Birth }\end{array}$ \\
\hline 9 & Neonatal blood spot screening & $\begin{array}{l}\text { Effective Midwifery Practice } \\
9\end{array}$ & Communication \\
\hline 10 & Blood sugar monitoring (adults) & $\begin{array}{l}\text { Effective Midwifery Practice } \\
2\end{array}$ & Communication \\
\hline 11 & Administering oral medication to neonates & $\begin{array}{l}\text { Effective Midwifery Practice } \\
12\end{array}$ & $\begin{array}{l}\text { Communication Medical Products } \\
\text { Management }\end{array}$ \\
\hline 12 & Administering topical medication to neonates & $\begin{array}{l}\text { Effective Midwifery Practice } \\
\qquad 12\end{array}$ & $\begin{array}{l}\text { Communication Medical Products } \\
\text { Management }\end{array}$ \\
\hline 13 & Administering IM Vitamin $\mathrm{K}$ to neonates & $\begin{array}{l}\text { Effective Midwifery Practice } \\
\qquad 12\end{array}$ & $\begin{array}{l}\text { Communication Medical Products } \\
\text { Management }\end{array}$ \\
\hline 14 & Blood sugar monitoring (neonates) & $\begin{array}{l}\text { Effective Midwifery Practice } \\
10\end{array}$ & Communication \\
\hline 15 & Preparing IV infusions for administration & $\begin{array}{l}\text { Effective Midwifery Practice } \\
\qquad 4 \text { and } 9\end{array}$ & Communication \\
\hline 16 & $\begin{array}{l}\text { Adding drugs to IV infusions and preparing IV infusion } \\
\text { pumps }\end{array}$ & $\begin{array}{l}\text { Effective Midwifery Practice } \\
12\end{array}$ & Communication \\
\hline
\end{tabular}


Table 2 Example question from evaluation

1) Using the Passport ensures that opportunities are found for students to practice vital skills prior to qualification.

\begin{tabular}{|l|l|l|l|}
\hline 1 & 2 & 3 & 4 \\
\hline Completely agree & Slightly agree & Slightly disagree & Completely disagree \\
\hline & & & \\
\hline
\end{tabular}

Comments:

Table 3 Evaluation form for the Pre-Qualifying Skills Passport

\begin{tabular}{|c|c|c|c|c|c|c|}
\hline & Statement & $\begin{array}{l}\text { Completely } \\
\text { agree }\end{array}$ & $\begin{array}{l}\text { Slightly } \\
\text { agree }\end{array}$ & $\begin{array}{l}\text { Slightly } \\
\text { disagree }\end{array}$ & $\begin{array}{l}\text { Completely } \\
\text { disagree }\end{array}$ & $\begin{array}{c}\text { No } \\
\text { answer }\end{array}$ \\
\hline 1 & $\begin{array}{l}\text { Using the Passport ensures that opportunities } \\
\text { are found for students to practice vital skills } \\
\text { prior to qualification. }\end{array}$ & 93 & 66 & 5 & 3 & 0 \\
\hline 2 & The Passport is easy to use. & 112 & 50 & 4 & 1 & 0 \\
\hline 3 & $\begin{array}{l}\text { The Passport helps me to know what is } \\
\text { expected of Newly Qualified Midwives in } \\
\text { terms of the identified skills. }\end{array}$ & 112 & 45 & 10 & 0 & 0 \\
\hline 4 & $\begin{array}{l}\text { I think that student midwives SHOULD NOT } \\
\text { undertake one or more of the skills identified } \\
\text { in the Passport. }\end{array}$ & 6 & 29 & 2 & 130 & 0 \\
\hline 5 & I think that more skills should be added. & 26 & 47 & 38 & 53 & 3 \\
\hline 6 & $\begin{array}{l}\text { Without the Passport some students may } \\
\text { qualify without trying out essential midwifery } \\
\text { skills. }\end{array}$ & 59 & 37 & 26 & 7 & 38 \\
\hline 7 & $\begin{array}{l}\text { I like the way that the Passport shows that the } \\
\text { student has the underpinning KNOWLEDGE } \\
\text { prior to actually trying out each skill. }\end{array}$ & 87 & 66 & 9 & 2 & 3 \\
\hline 8 & $\begin{array}{l}\text { I like the way that each skill is standardised } \\
\text { and described step-by-step. }\end{array}$ & 112 & 49 & 1 & 1 & 4 \\
\hline 9 & $\begin{array}{l}\text { I would prefer it if mentors were able to teach } \\
\text { the students what they want to teach them - } \\
\text { without the use of Passports such as the Pre- } \\
\text { Qualifying Skills Passport }\end{array}$ & 9 & 28 & 56 & 68 & 6 \\
\hline
\end{tabular}

Table 4 Responses from participants by job title

\begin{tabular}{|l|l|l|l|l|l|}
\hline $\begin{array}{l}\text { Year } 2 \text { Midwifery } \\
\text { Student }\end{array}$ & $\begin{array}{l}\text { Year 3 Midwifery } \\
\text { Student }\end{array}$ & $\begin{array}{l}\text { Newly Qualified } \\
\text { Midwife <2 yrs }\end{array}$ & $\begin{array}{l}\text { Midwifery Sign-off } \\
\text { Mentor }\end{array}$ & $\begin{array}{l}\text { Midwifery } \\
\text { Lecturer }\end{array}$ & \begin{tabular}{l} 
Midwifery Manager \\
\hline 47
\end{tabular} \\
\hline
\end{tabular}

Figure 2 


\section{STANDARD STATEMENT}

\section{Pre-Qualifying Skill No. 2}

\section{Membrane sweep}

\section{SECTION 1}

\section{PREPARING FOR THE SKILL}

University preparation required prior to undertaking this skill in practice settings

In preparation for practising this skill the following will be studied and practised in University.

Lecture(s) (and associated guided reading) relating to:

- Current NICE guidelines and local policies / guidelines on Induction of Labour and Membrane Sweeps.

- The Bishop score.

- The information that midwives should share with women in order that they can make an informed choice regarding membrane sweeps.

- When to offer a membrane sweep:

- The correct procedure for documenting a membrane sweep.

Demonstration and practice in the skills lab of:

- Vaginal examination and simulation of membrane sweeping.

On completion of the above the University teacher will sign below to indicate that the student is ready to start practicing the skill in the practice setting:

\begin{tabular}{|l|l|l|}
\hline Student's signature & Teacher's signature & Date \\
\hline & & \\
\hline
\end{tabular}

N.B. THIS MUST BE SIGNED AS COMPLETED PRIOR TO THE STUDENT ATTEMPTING THE SKILL 


\section{SECTION 2 ACHIEVING THE SKILL}

\section{Step - by step guide for mentors}

As a mentor assessing this students' competence in undertaking a membrane sweep, please use the competence descriptors below and 'sign it off' when you believe that the student has achieved competence in this skill.

\section{Competence descriptors}

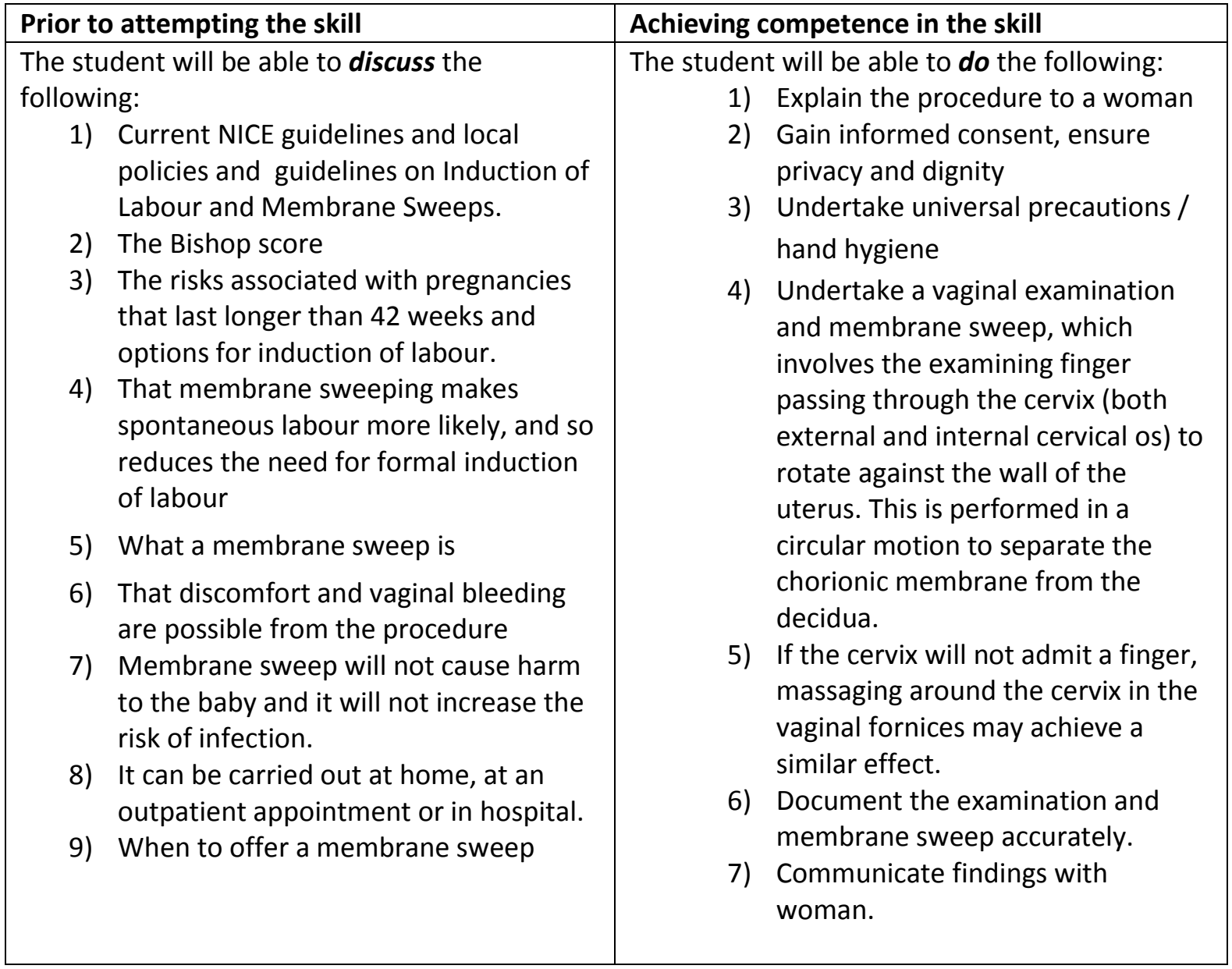

I confirm that has demonstrated competence in this skill

set out in the competence descriptors above.

Signed.

Name (printed)

Date 
